\title{
A Comparative Analysis for forecasting the NAV's of Indian Mutual Fund using Multiple Regression Analysis and Artificial Neural Networks
}

\author{
E. Priyadarshinil and A. Chandra Babu
}

\begin{abstract}
Regression analysis is one of the popular method used for prediction and forecasting. Regression analysis is also used to understand which among the independent variables are related to the dependent variable, and to explore the forms of these relationships. In recent times, Artificial Neural Network has been successfully used in modeling financial time series due to its ability to model easily any type of parametric or nonparametric process and automatically and optimally transform the input data. In this paper, the interaction effects of the various economic factors influencing the Net Asset Values of the Indian Mutual Funds was evaluated and the future NAV's were forecasted for the following years using Regression Analysis and Artificial Neural Network and the performance of the two methods were compared based on standard statistical measures such as MAPE, RMSE, etc. Validity of the models were tested and the future NAV values of the mutual fund has been forecasted.
\end{abstract}

Index Terms-Prediction, time series. Multiple Regression Analysis, Artificial Neural Networks.

\section{INTRODUCTION}

Campbell (1987), French et.al. (1987) Fama and French ( 1989), Balvers et.al ( 1990), Been, Glosten and Jaganathan, (1990) have showed empirical evidence that macroeconomic variables can predict market returns. By using the concept of co- integration, first introduced by Eangle et.al(1987), the empirical long run relationships between stock market indices and financial variables can be investigated. Chan and Chen (1992), Chang and Lewellen (1984), Kon andJen (1979), Lee and Rahman (1991), Treynor and Mazuy (1966) have used multiple regression techniques as a tool for analysis.Recently several researchers like Baestaens et. al. (1995), Kaastra Ibeling and others (1996), Katsurelis(1998), Kamath (1999 and 2002) recommend the use of Artificial Neural Network (ANN) for investigating the co-integrating relationship as well as forecasting in capital markets, which has tremendous promise in terms of methodology. Chiang, Urban and Baldridge (1996) have used neural network for forecasting the net asset values of the selected mutual funds in U. S. market. Kamath(2002) uses Artificial Neural Network (ANN) to examine the relationship of macroeconomic factors to the returns of individual assets.Bhattacharya and Mukherjee (2002), Rao and

Manuscript received July 20, 2012; August 21, 2012.

E. Priyadarshini is with Sathyabama University, Chennai, India. She is at present doing her research in Sathyabama University. (email:priyaeb@gmail.com).

A. Chandrababu is with Noorul Islam, University, Kumarakoil, India. (email: chandrababu_a@yahoo.co.in).
Rajeswari (2000) have used advanced methods in econometrics to study the same relationship.

\section{MulTiPle REGRESSION ANALYSIS}

Regression analysis is a statistical tool for the investigation of relationships between variables. Regression techniques has been of great importance to the field in Econometrics. Usually, the investigator seeks to ascertain the causal effect of one variable upon another. To analyse such issues, the investigator assembles data on the underlying variables of interest and employs regression to estimate the quantitative effect of the causal variables upon the variable that they influence. This typically assesses the "statistical significance" of the estimated relationships, that is, the degree of confidence that the true relationship is close to the estimated relationship. Increase in the number of independent variables in the model will increase the closeness to real trend. Multiple regression looks at each individual independent variable and tests whether it contributes significantly to the way the regression describes the data. Step-wise regression is the most frequently used regression method.

The general multiple regression equation is

$$
Y=a+b_{1} x_{1}+b_{2} x_{2}+\ldots . . b_{\mathrm{n}} x_{\mathrm{n}}
$$

where $Y=$ Estimated value corresponding to the dependent variable, $a=y$ intercept

$$
x 1, x 2 \ldots x \mathrm{n}=\text { values of } n \text { independent variable. }
$$

\section{ARTIFICIAL NEURAL NETWORK}

ANN is a branch of computational intelligence that employs a variety of optimization tools to learn from past experiences and use this prior training to predict and identify new patterns. Neural network theory grew out of Artificial Intelligence research that had designed machines with cognitive ability which is popularly known as Neural Network. It is composed of parallel computing units called Neurons. These neurons can be connected in various ways to form different Neural Network architectures.

An Artificial Neural Network (ANN) is information processing system whose performance characterizes biological neural networks. ANNs are mathematical models of neural biology based upon the assumption that:

1) Information processing occurs at many simple elements called neurons. 
2) Signals are passed between neurons over connection links.

3) Each connection link has an associated weight, which multiplies the signal transmitted.

4) Each neuron applies an activation function (usually non linear) to its net input (sum of weighted input signals) to determine its output signal.

ANN is characterized by (1) a pattern of connections between the neurons called its architecture. (2) Method of determining the weights on the connections called training algorithm and (3) activation or transferring function from one neuron to another neuron. Neurons in ANN are organized in single or multi layers. The current work without emphasizing on these strategies assumes learning rate, momentum, epochs, error tolerance and target randomly. Back Propagation Algorithm is the most commonly used algorithm for developing ANN models for financial data(Yohong Li,2010).

In the development of feasible NN analysis all the factors are used to ascertain the effect and to predict the trend of net asset values. All the input values are normalized using the MinMax Table.
Norm value, $N=\frac{[\text { Original value }- \text { Minimum value }]}{\text { [Maximumvalue - Minimum value] }}$

Back-propagation (BP) $\mathrm{NN}$ is used in the study(Zhou Yixin, Jie Zhang,2010).A gradient descent rule is adopted in the programme of training set. $\mathrm{NN}$ is set to 10000 iterations, learning rate of 0.6 , increase in learning rate of 0.9 with 1 hidden layer and one linear output. Training stops when convergence required root-mean-square-error is below 0.0001 percent. The share of influence of selected indicators is established to know which of the factors has the most effect on the output.

\section{DATA ANALYSIS}

To measure the magnitude of linear relationship of Net Asset Values $(Y)$ on individual factor $(X)$, correlation analysis is performed.The period for analysis is taken from Jan 2003 to Dec 2008 for the Indian Mutual Fund -Sahara -Growth option (equity).

TABLE I:TABLE SHOWING THE REGRESSION COEFFICIENTS

\begin{tabular}{|c|c|c|c|c|c|}
\hline \multicolumn{3}{|c|}{ Unstandardized Coefficients } & \multirow{2}{*}{$\frac{\text { Std Coeff }}{\text { Beta }}$} & \multirow[t]{2}{*}{$\mathrm{t}$} & \multirow[t]{2}{*}{ Sig. } \\
\hline & $\mathrm{B}$ & Std. Error & & & \\
\hline (Constant) & -6.191 & 11.236 & & -.551 & .583 \\
\hline BSE Index & .021 & .000 & -.048 & -2.18 & .031 \\
\hline NSE Index & .012 & .001 & .740 & 11.85 & .000 \\
\hline $\operatorname{GDP}(\%)$ & .115 & .592 & .005 & .193 & .847 \\
\hline Inflation $(\%)$ & .129 & .204 & .016 & .635 & .527 \\
\hline Crude oil (\$) & .078 & .036 & .080 & 2.155 & .034 \\
\hline $\begin{array}{l}\text { Gold / Gm } \\
\text { (Rs) }\end{array}$ & .017 & .003 & .301 & 4.834 & .000 \\
\hline $\begin{array}{l}\text { Silver / Gm } \\
(\mathrm{Rs})\end{array}$ & -.196 & .176 & -.069 & -1.11 & .270 \\
\hline Doll Eq (Rs) & -.076 & .252 & -.009 & -.300 & .765 \\
\hline
\end{tabular}

\section{A . Multiple Regression Analysis}

The following Macroeconomic variables were chosen as predictors : BSE Index, NSE Index, GDP (\%), Inflation (\%), Crude oil (\$), Gold / Gm (Rs), Silver / Gm (Rs), Dollar Eq (Rs) and the dependent variable is Net Asset Value of Sahara Mutual Fund. The multiple regression equation is given by

$$
\begin{aligned}
& Y=-6.191+.021 \mathrm{BSE}+.012 \mathrm{NSE}+.115 \mathrm{GDP}+.129 \mathrm{INF} \\
& +.078 \mathrm{CRU}+.017 \mathrm{GLD}-.196 \mathrm{SIL}-.076 \mathrm{DOL}
\end{aligned}
$$

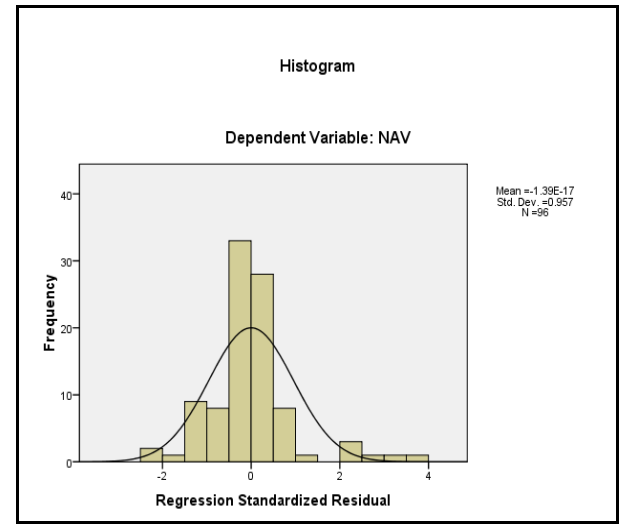

Fig. 1. Histogram plot of residuals 


\section{Normal P.P Plot of Regression Standardized Residual} Dependent Variable: NAV

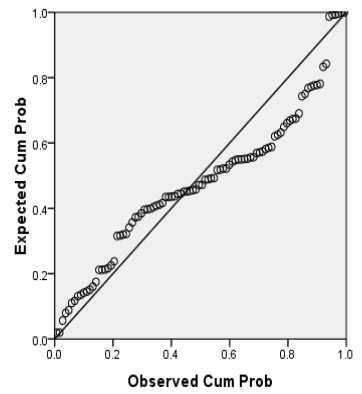

Fig. 2. Normal $\mathrm{P}-\mathrm{P}$ plot of the residuals

\section{B. Artificial Neural Networks}

In this feed forward network used to predict the future NAV of Sahara Mutual Fund, the input layer consists of 8 inputs and the rescaling method used is normalized. The hidden layer consists four units and the activation function used is the hyperbolic tangent. The output is the NAV of the mutual fund and the activation function used is the identity function. The training period for the network is taken from Jan 2003 to Dec 2006 and the testing period is taken from Jan 2007 to Dec 2009.

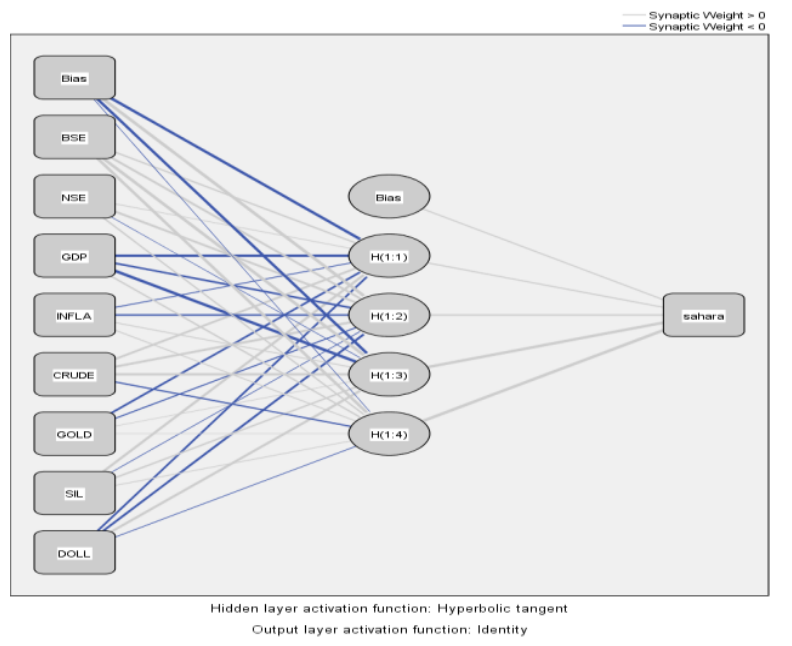

Fig. 3. Network diagram of the artificial neural networks

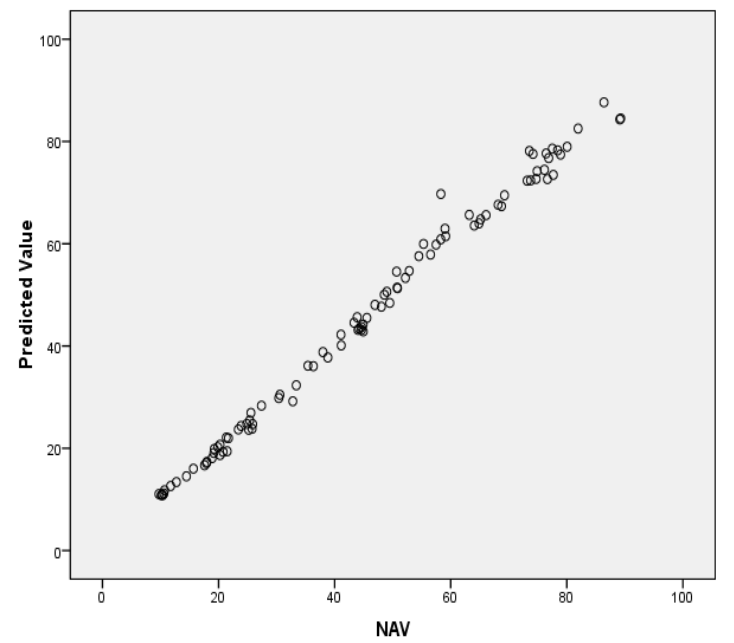

Fig. 4. Plot of actual versus predicted NAV of sahara mutual fund

\section{RESUlTS}

The outcome of the statistical and NN models are validated with the market price in 2009 and 2010 and and the table shows the various error estimates for both the methods. It can be clearly seen that ANN outperforms Multiple Regression Analysis. Hence it can be successfully used in the prediction of Net Asset Values of the Mutual Funds.

TABLE II: ERROR ESTIMATES OF MULTIPLE REGRESSION ANALYSIS AND ARTIFICIAL NEURAL NETWORK

\begin{tabular}{|c|c|c|}
\hline $\begin{array}{c}\text { ERROR } \\
\text { ESTIMATES }\end{array}$ & REGRESSION & $\begin{array}{c}\text { ARTIFICIAL } \\
\text { NEURAL } \\
\text { NETWORKS }\end{array}$ \\
\hline MAE & 2.101 & 1.432708 \\
\hline MSE & 7.9384 & 4.4486 \\
\hline RMSE & 2.8175 & 2.101 \\
\hline MAPE & 5.25 & 4.1 \\
\hline MPE & 0.586109 & 0.09497 \\
\hline
\end{tabular}

\section{CONCLUSION AND FUTURE WORK}

This paper depicts the fact that Neural Networks outperforms Multiple Regression Analysis in forecasting the Net Asset Values of the mutual funds. The forecasting ability of models is accessed on the MAE, MSE, RMSE, MAPE and MPE.

The field of neural networks has diverse opportunities for future research in the field of management. The future scope for the research is to improve further the performance of Neural Network, for this application, perhaps through better training methods, architecture selection, or input values.

\section{REFERENCES}

[1] J. Y. Campbell, "Stock Returns and the Term Structure," Journal of Financial Economics, vol. 18, pp. 3-37, 1987.

[2] K. R. French, G. S. Schwert, and R. F. Stambaugh, "Expected Stock Returns and Volatility," Journal of Financial Economics, vol. 19, pp. 3-30, 1987.

[3] E. F. Fama and K. R. French, "Business Conditions and the Expected Returns on Stocks and Bonds," Journal of Financial Economics, vol. 25, pp. 23-49, 1989.

[4] R. J. Balvers, T. F. Cosimano, and B. McDonald, "Predicting Stock Returns in an Efficient Market," Journal of Finance, vol. 45, pp. 1109-1128, 1990.

[5] L. R. Glosten, R. Jagannathan, and D. E. Runkle, "On the Relation Between the Expected Value and the Volatility of the Nominal Excess Return on Stocks," Jounal of Finance, vol. 48, pp. 17791801,1993

[6] M. H. Pesaran and A. Timmermann, "A Recursive Modelling Approach to Predicting U.K. Stock Returns," Economic Journal, vol. 110, pp. 159-191, 2000.

[7] N. F. Chen, R. Roll, and S. Ross, "Economic Forces and the Stock Market," Journal of Business, vol. 59, pp. 383-403, 1986.

[8] E. F. Fama, "Stock Returns, Expected Returns, and Real Activity," Journal of Finance, vol. 45, pp. 1089-1108, 1990.

[9] E. C. Chang and W. G. Lewellen, "Market Timing and Mutual Fund Investment Performance," Journal of Business, vol. 57, pp. 57-62, 1984.

[10] S. J. Kon and F. C. Jen, "The Investment Performance of Mutual Funds: An Empirical Investigation of Timing, Selectivity and Market Efficiency," Journal of Business, vol. 52, pp. 263-289, 1979.

[11] M. V. Kamath, "Emperical Investigation of Multifactor Asset Pricing Model Using Artificial Neaural Networks," NSE Research Initiative, Paper 10, 2002.

[12] Kaastra, Ibeling, and Milton, "Designing a Neural Network for Forecasting Financial and Economic Time Series," Neurocomputing, vol. $10,1996$. 
[13] J. E. Kutsurelis, Forecasting Financial Markets Using Neural Networks: An Analysis of Methods and Accuracy, MS Thesis, US Naval Postgraduate School, 1998.

[14] K. C. Rao and A. Rajeswari, Macro Economic Factors and Stock Prices in India: A Study, Paper presented in the Capital Markets Conference 2000,Mumbai, 2000.
[15] Z. Yixin and J. Zhang, "Stock Data Analysis Based on BP Neural Network," in Proc. Second International Conference on Communication Software and Networks, 2010, pp.396-399.

[16] Y. Li, "Applications of Artificial Neural Networks in Financial Economics: A Survey,International Symposium on Computational Intelligence and Design (ISCID)," in Proc. Conference Publications, vol. 1,pp. $211-214,2010$. 